\title{
Sensitive PCR-based Detection of Apple Chlorotic Leaf Spot Virus Heterogenous in Apple Trees
}

\author{
Kenji S. NAKAHARA ${ }^{*}$, Kouji YOSHIDA ${ }^{2}$, Kouichi SUZAKI ${ }^{3}$, \\ Nobuyuki YOSHIKAWA ${ }^{4,5}$ and Tsutae ITO $^{2}$ \\ 1 Research Faculty of Agriculture, Hokkaido University (Sapporo, Hokkaido 060-8589, Japan) \\ 2 Apple Research Station, National Institute of Fruit Tree Science, National Agriculture and Food \\ Research Organization (NARO) (Morioka, Iwate 020-0123, Japan) \\ 3 Grape and Persimmon Research Station, National Institute of Fruit Tree Science, NARO \\ (Akitsu, Hiroshima 739-2494, Japan) \\ 4 The United Graduate School of Agricultural Sciences, Iwate University (Morioka, Iwate 020- \\ 8550, Japan) \\ 5 Plant Pathology Laboratory, Faculty of Agriculture, Iwate University (Morioka, Iwate 020- \\ 8550, Japan)
}

\begin{abstract}
This paper presents a useful process for the detection of Apple chlorotic leaf spot virus (ACLSV) in apple trees. The 3'-terminal 1.8-kb genomic cDNAs of 15 ACLSV isolates, of which 11 induce a decline (of varying severity) in the condition of inoculated Malus prunifolia var. ringo rootstock and four do not, were amplified by reverse transcription (RT) coupled with polymerase chain reaction (PCR). Single-strand conformation polymorphism analysis of the cDNAs revealed that most of the isolates inducing the decline were composed of at least two to four sequence variants per apple tree, whereas isolates inducing no decline were occupied with a major type sequence. Direct sequencing of the cDNAs showed heterogeneity in the nucleotide sequence of the analyzed region; most of the variation in these positions appeared to specify the same amino acids upon translation of the $50 \mathrm{~K}$ protein and capsid protein $(\mathrm{CP})$. To detect all isolates, degenerate primers were designed with consideration of the sequence varieties of the viral genomes. RT-nested PCR and its improved methods have a $10^{4}$-fold higher sensitivity than conventional RT-PCR, and consistently amplify ACLSV genomic cDNA in RNA extracts from apple leaf and bark during growing and dormant seasons, respectively.
\end{abstract}

Discipline: Plant disease

Additional key words: Topworking disease

\section{Introduction}

Apple chlorotic leaf spot virus (ACLSV) is the type species of the genus Trichovirus ${ }^{13}$, which is composed of a filamentous particle containing a single coat protein of $22 \mathrm{~K}$ and a polyadenylated plus-sense ssRNA of $7.5 \times$ $10^{3}$ nucleotides $^{23}$. Although ACLSV is latently distributed worldwide in most fruit trees, including apple, peach, pear, plum, cherry, and apricot, it induces a large variety of symptoms in sensitive fruit trees ${ }^{3,10}$. In Japan, ACLSV is one of the causative agents of apple topworking disease, which induces bark necrosis and stem pitting of the Maruba Kaido (Malus prunifolia var. ringo) rootstock leading to lethal decline in the apple trees on which it grows ${ }^{20}$.

A program of disseminating virus-free material controls ACLSV infection because of the absence of known natural vectors for this virus. Reliable detection of ACLSV is thus important in the implementation of the program. Graft bioassay with sensitive woody plants and enzyme-linked immunosorbent assay (ELISA) have been used to detect ACLSV ${ }^{21,22}$. However, both assays still have significant problems in terms of the length of time required for indexing or sensitivity. Similar to many viruses infecting woody plants, these problems are due to the low and uneven concentration of the virus

*Corresponding author: e-mail knakahar@res.agr.hokudai.ac.jp Received 22 January 2010; accepted 24 January 2011. 
depending on the season ${ }^{8}$, its frequent uneven distribution in infected plants ${ }^{4}$, and diversity among virus isolates, which results in variation in the responses of indicator plants and the antibodies raised against ACLSV ${ }^{20,21}$.

The development of reverse transcription (RT) coupled with polymerase chain reaction (PCR) assay for detecting $\mathrm{ACLSV}^{2,9}$ provided rapidity and sensitivity to potentially overcome some of the problems mentioned above. For other viruses in their woody hosts, more reliable and sensitive detection was achieved using methods based on nested PCR ${ }^{1,14,15}$. However, the sensitivity and specificity of the RT-PCR assay depended on complementarity between short oligonucleotide primers and target (in this case, viral genomic) nucleotide sequences. Complete nucleotide sequences of ACLSV genomes were reported for a plum isolate ${ }^{5}$, an apple isolate ${ }^{17}$, and a cherry isolate ${ }^{6}$. The overall nucleotide sequence homology levels among these isolates were between 76 and $82 \%$. The coat protein gene appeared to be the most conserved of the ACLSV-encoding genes, with identity levels ranging between 87 and 93.3\%. Among ACLSV isolates from apple, partial nucleotide sequence homology levels between 81 and $93 \%$ were also reported ${ }^{2,9}$. Hence, genomic diversity among virus isolates leading to mismatches between oligonucleotide primers and the viral genome could cause difficulties in detecting these isolates with RT-PCR.

Moreover, isolates of Apple stem grooving virus (ASGV), which is a member of the genus Capillovirus and another causal agent of topworking disease, were found to have at least two to four sequence variants, which ranged from 53.2 to $99.3 \%$ homology in the open reading frame-1 (ORF1)-encoded protein in infected fruit trees, according to sequencing and single-strand conformation polymorphism (SSCP) analyses ${ }^{11,12}$. This raised the question of whether ACLSV isolates were also comprised of several sequence variants in apple trees. Yanase ${ }^{20}$ previously isolated ACLSV strains latent to $M$. prunifolia var. ringo from a Golden Delicious tree known to carry the strain that induces a decline in the condition of $M$. prunifolia var. ringo, suggesting that both strains coexisted in the apple tree, as does ASGV in fruit trees.

In this study, we first demonstrated that most ACLSV isolates had genetic heterogeneity in an apple tree. Direct sequencing of RT-PCR products from viral genomes provided the information about sequence diversities among the isolates for the design of degenerate primers; we then attempted to develop a sensitive nested PCR-based assay using the primers for virus-free certification schemes.

\section{Materials and methods}

\section{Virus isolates, host plants}

The 15 ACLSV isolates used in this study are listed in Table 1. Seven isolates were collected from apple trees in commercial orchards in Japan, and five isolates were collected from apple trees in our experimental orchard (Apple Research Station, NIFTS-NARO, Morioka) containing varieties introduced from abroad. B 81, MO-31, and MO-41 isolates were kindly provided by Dr. G. I. Mink (Washington State University). Of these isolates, 11 induced decline in M. prunifolia var. ringo, whereas the other four induced no symptoms (Table 1). Each of these isolates was maintained in apple trees on apple seedling rootstocks in our orchard.

\section{RNA preparation}

Total RNA was extracted from $100 \mathrm{mg}$ apple tissue using an RNeasy Plant mini kit (Qiagen, Hilden, Germany), according to the manufacturer's protocol. This method utilizes a silica gel-based membrane to selectively bind the total RNA in conjunction with microspin technology. The total RNA in $50 \mu 1$ distilled water was stored at $-80^{\circ} \mathrm{C}$ until used for viral cDNA amplification.

\section{Viral cDNA synthesis and amplification}

First-strand cDNA was synthesized using avian myeloblastosis virus reverse transcriptase XL (AMV RT $\mathrm{XL}$, Life Sciences) as follows: reaction mixtures $(20 \mu \mathrm{l})$ containing $1 \times$ reaction buffer $(50 \mathrm{mM}$ Tris- $\mathrm{HCl}, \mathrm{pH}$ 8.3, $100 \mathrm{mM} \mathrm{KCl}, 4 \mathrm{mM}$ DTT, $10 \mathrm{mM} \mathrm{MgCl}_{2}$ ), $1 \mathrm{mM}$ deoxynucleotide triphosphates, $0.125 \mu \mathrm{M}$ oligo dT (15mer), 8 units of AMV-XL, and $1 \mu \mathrm{l}$ (approx. $0.2 \mu \mathrm{g}$ ) total RNA were incubated at $42{ }^{\circ} \mathrm{C}$ for $1 \mathrm{~h}$. Viral cDNA was amplified by PCR as follows: mixtures containing 4 $\mu 1$ cDNA solution, $1 \times$ Ex-Taq buffer including $2 \mathrm{mM}$ $\mathrm{Mg}^{2+}$ (TaKaRa, Otsu, Japan), $0.2 \mathrm{mM}$ deoxyribonucleotide triphosphates, primer pairs $(0.2 \mu \mathrm{M}$ each; Fig. $1, \mathrm{P}$ 1, P2, M1, and C4), and 1.25 units of Ex-Taq DNA polymerase (TaKaRa) were incubated for 30 cycles of denaturation at $94^{\circ} \mathrm{C}$ for $30 \mathrm{~s}$, annealed at $60^{\circ} \mathrm{C}$ for 1 min, and elongated at $72^{\circ} \mathrm{C}$ for $2 \mathrm{~min}$. The mixtures were incubated at $72^{\circ} \mathrm{C}$ for $7 \mathrm{~min}$ following completion of the last cycle. The PCR product was stored at $-20^{\circ} \mathrm{C}$ until electrophoresis and nucleotide sequencing.

\section{SSCP analysis}

The fluorescent (Texas Red)-labeled cDNA for SSCP analysis was amplified from the PCR product described above. PCR was performed as described above using $0.2 \mu \mathrm{l}$ of the PCR product and Texas Red-labeled 
Table 1. Amplification of the 3'-terminal genome regions of ACLSV isolates in apple trees ${ }^{1}$ by reverse transcription polymerase chain reaction (RT-PCR)

\begin{tabular}{|c|c|c|c|c|c|c|c|}
\hline \multirow[t]{2}{*}{ Isolate $^{1)}$} & \multirow{2}{*}{$\begin{array}{l}\text { Present host } \\
\text { (apple cultivar) }\end{array}$} & \multirow[t]{2}{*}{ Origin } & \multirow{2}{*}{$\begin{array}{l}\text { Decline of } \\
\text { M. prunifolia var. ringo } o^{4)}\end{array}$} & \multicolumn{4}{|c|}{ Primer pairs ${ }^{2)}$} \\
\hline & & & & P1-M1 & $\mathrm{P} 1-\mathrm{C} 4$ & P2-M1 & $\mathrm{P} 2-\mathrm{C} 4$ \\
\hline P-195 & Indo & Fukushima & + & + & + & + & + \\
\hline P-195L & Indo & Fukushima & + & + & + & + & + \\
\hline PK-32 & Fuji & Aomori & + & + & + & + & + \\
\hline PK-51 & Royal Gala & New Zealand & + & + & + & + & + \\
\hline P-142 & Golden Delicious & Akita & + & + & + & + & + \\
\hline P-143 & Golden Delicious & Akita & + & + & + & + & + \\
\hline MK-8 & NY 58-22 & USA & + & + & + & + & + \\
\hline B-81 & Unknown & USA & + & + & + & + & + \\
\hline P-202 & Seedling & Iwate & + & + & + & + & + \\
\hline PK-5 & Seedling & Niigata & + & + & + & + & + \\
\hline PI-25 & Indo & Gunma & + & + & + & + & + \\
\hline MK-1 & Bin $\mathrm{Zi} 1$ & China & - & + & + & + & + \\
\hline MK-9 & Himekokko & Gunma & - & + & + & + & + \\
\hline MO-31 & Seedling & USA & - & + & + & + & + \\
\hline MO-41 & Hopa Crab & USA & - & + & - & + & - \\
\hline
\end{tabular}

primers, P4 and M2 (Fig. 1), which were prepared according to the manufacturer's protocol (Hitachi, Tokyo, Japan). After amplification was confirmed by agarose gel electrophoresis, fluorescent-labeled cDNA was stored at $-20^{\circ} \mathrm{C}$ until analyzed by SSCP. The fluorescence-labeled viral cDNA $(0.5 \mu \mathrm{l})$ amplified with the primers P4 and M2 was mixed with $10 \mu \mathrm{l}$ of a solution of $95 \%$ formamide, $10 \mathrm{mM} \mathrm{NaOH}$, and incubated at $94{ }^{\circ} \mathrm{C}$ for $3 \mathrm{~min}$. The denatured cDNA solution $(3 \mu \mathrm{l})$ was electrophoresed in polyacrylamide gels $(0.5 \times \mathrm{MDE}$ gel solution (FMC), $0.6 \times \mathrm{TBE}, 5 \%$ glycerol) at 20, 25, or $40^{\circ} \mathrm{C}$ at $1000 \mathrm{~V}$ for $6 \mathrm{~h}$, with collection of fluorescence signal data using an SQ-5500 DNA sequencer (Hitachi).

\section{Direct nucleotide sequencing of PCR products}

The viral cDNA amplified by PCR with P1 and M 1 (Fig. 1) was directly sequenced using a BigDye Terminator Cycle Sequencing FS Ready Reaction Kit (Applied Biosystems, Foster City, USA) with primers for sequencing (Fig. 1). P1 and M1 primers were first used for direct sequencing, and the inner degenerate primers (sense primers P2-P5 and anti-sense primers M2-M7) were sequentially designed corresponding to a region relatively well-conserved among the nucleotide sequences investigated. To dismiss the possibility that PCR and sequencing errors affected the sequence determination, the nucleotide sequence was investigated by sequencing more than twice using different primers, and then the nucleotides at each position in the cDNA sequence were determined to be a consensus among the nucleotides designated at least twice by sequencing with the primers: For example, if sequencing with four primers designate the nucleotide at one position as $\mathrm{R}(\mathrm{A} / \mathrm{G})$, $\mathrm{G}, \mathrm{C}$, and D (A/G/T), respectively, the consensus nucleotide will be determined to be R. Sequencing analysis was conducted with the DNASIS program (Hitachi Software Engineering, Tokyo, Japan).

\section{RT-PCR procedures for ACLSV detection.}

(1) Degenerate Primers

To detect ACLSV isolates consistently, degenerate 


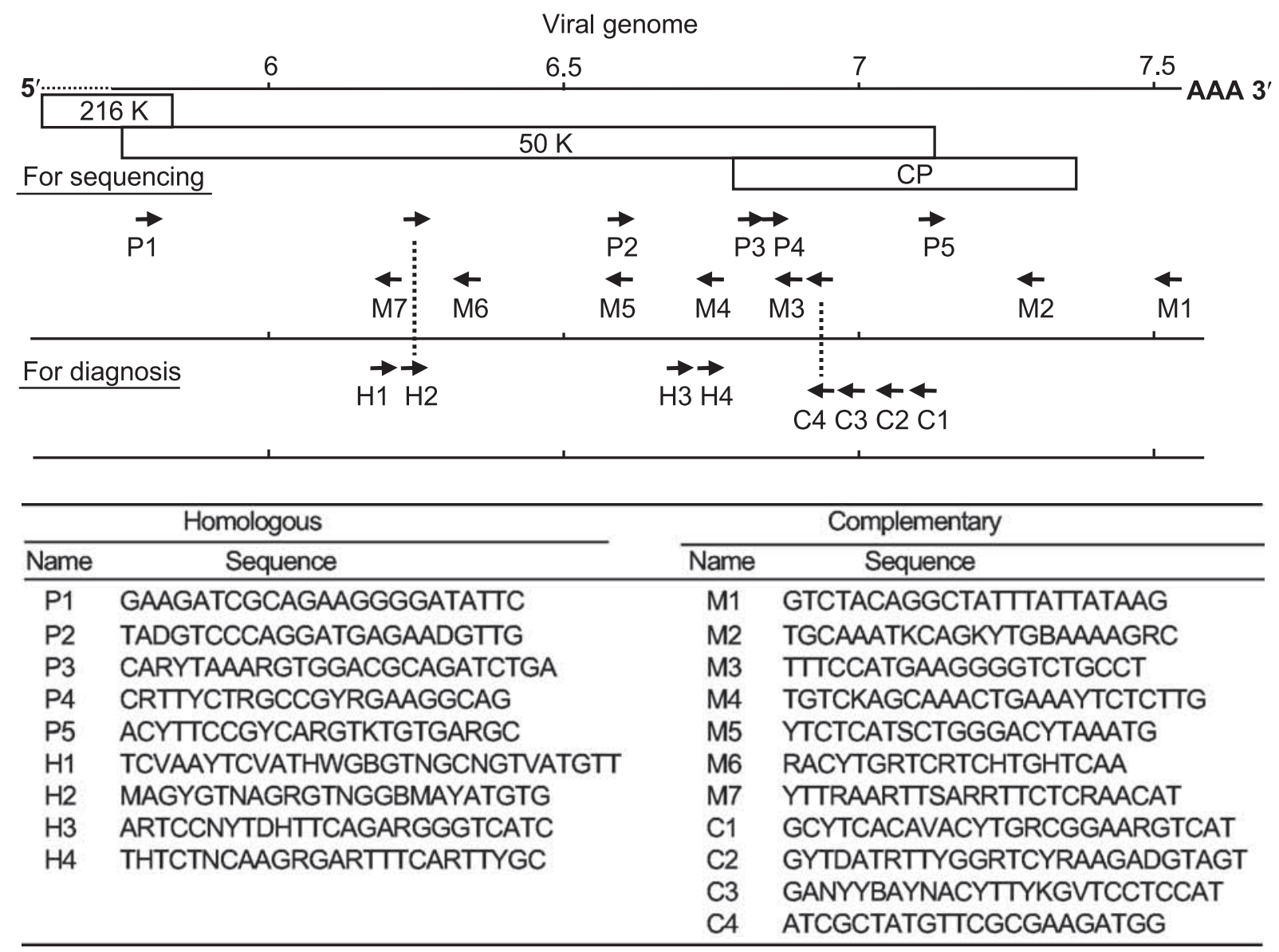

Fig. 1. Schematic representation of the 3'S-terminal region of the ACLSV genome, composed of parts of $216 \mathrm{~K}, 50 \mathrm{~K}$, and $\mathrm{CP}$ genes, and the primer sequences used in this study

Four primers, P1, P2, M1, and C4, were designed corresponding to the relatively well-conserved regions among three complete nucleotide sequences of ACLSV genomes reported previously ${ }^{5,6,17}$ and another from apple strain MO- $5^{19}$, latent to $M$. prunifolia var. ringo. The other primers were designed corresponding to the relatively well-conserved regions among two complete nucleotide sequences of apple strains mentioned above, P-205 ${ }^{17}$ and MO- $5^{19}$, and partial nucleotide sequences of virus isolates investigated in this study. The primers P1-P5 and M1-M7 were used for sequencing viral cDNAs amplified with primers P1 and M1. The primers $\mathrm{H} 1, \mathrm{H} 3, \mathrm{H} 4$, and $\mathrm{C} 1-\mathrm{C}$ 3 were used for detection of ACLSV in apple trees. The primers $\mathrm{H} 2$ and $\mathrm{C} 4$ were used for both purposes. In nucleotide sequences of primers, symbols are as follows, $\mathrm{Y}$ : $\mathrm{C}$ or $\mathrm{T}$; R: A or R; M: A or C; W: A or T; K: G or T; S: G or C; B: G, T, or C; D: A, G, or T; H: A, T, or C; V: A, G, or $\mathrm{C} ; \mathrm{N}: \mathrm{A}, \mathrm{G}, \mathrm{T}$, or $\mathrm{C}$.

primers (sense primers $\mathrm{H} 1-\mathrm{H} 4$ and anti-sense primers $\mathrm{C}$ 1-C4 ) were designed according to results of direct sequencing.

\section{(2) RT-PCR}

A GeneAmp EZ rTth RNA PCR kit was used according to the manufacturer's protocols (Applied Biosystems). Both RT and PCR were performed in one tube and one solution using one enzyme, rTth DNA polymerase. Reaction mixtures $(20 \mu \mathrm{l})$ included $1 \mu \mathrm{l}$ total RNA and $0.45 \mu \mathrm{M}$ each primer (Fig. 1, H4 and C4).

(3) RT-nested PCR (RT-nPCR)

RT and first PCR were performed as RT-PCR, ex- cept for reducing the volume of the reaction mixtures to $5 \mu 1$. Then, $0.2 \mu 1$ total RNA was used as a template in the reaction. A second PCR was performed in the same tube by adding $95 \mu \mathrm{l}$ of a mixture containing $1 \times \mathrm{Ex}$ Taq buffer, $0.2 \mathrm{mM}$ deoxyribonucleotide triphosphates, $0.45 \mu \mathrm{M}$ each primer (P1 and M1 for first PCR, and P2 and $\mathrm{C} 4$ for second PCR in Fig. 4; H3 and C3 for first PCR and H4 and C4 for second PCR in Fig. 5), and 2.5 units Ex-Taq DNA polymerase (TaKaRa). The mixture was subjected to 35 cycles of denaturation at $94{ }^{\circ} \mathrm{C}$ for $30 \mathrm{~s}$, annealing at $60^{\circ} \mathrm{C}$ for $30 \mathrm{~s}$, and elongation at $72^{\circ} \mathrm{C}$ for $2 \mathrm{~min}$, with a final extension step at $72^{\circ} \mathrm{C}$ for 

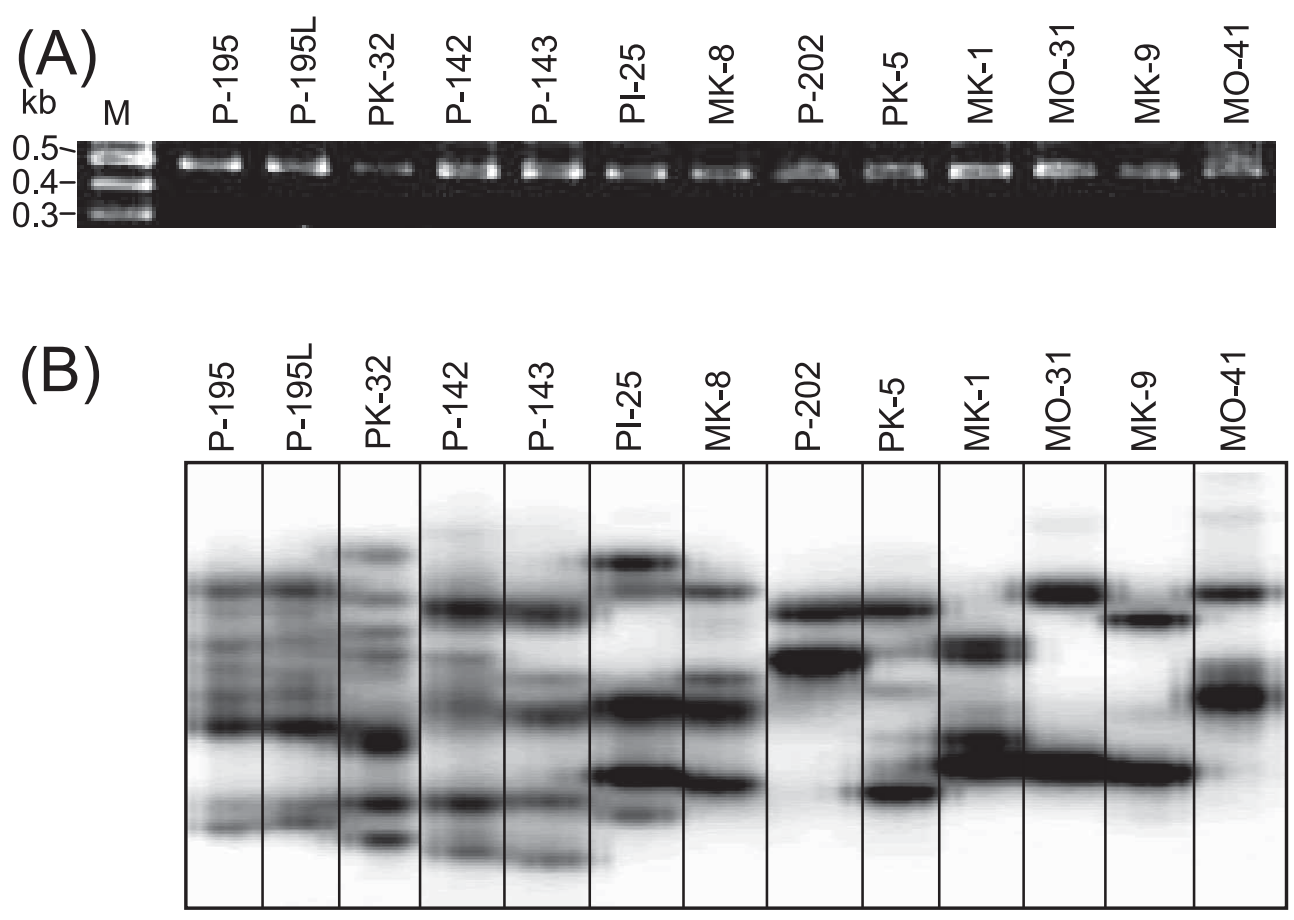

Fig. 2. Analysis of genomic heterogeneity of ACSLV in apple trees

(A) The viral cDNAs amplified with primers P4 and M2 from the initial PCR products with P1 and M1 of 13 virus isolates, P-195 to MO-41 (lanes P-195 to MO-41), were electrophoresed in $1.5 \%$ agarose gels. Lane $\mathrm{M}$ is 100 -bp ladder DNA molecular weight markers. The cDNAs were visualized by ultraviolet illumination after staining with ethidium bromide. (B) The viral cDNAs amplified with primers P4 and M2 from 13 virus isolates, P-195 to MO-41 (lanes P-195 to MO41 , were analyzed by single-strand conformation polymorphism. Electrophoresis was performed at $25^{\circ} \mathrm{C}$.

7 min following completion of the last cycle. The PCR product was stored at $-20{ }^{\circ} \mathrm{C}$ until electrophoresis.

(4) RT-dual-primed nested PCR (RT-dpnPCR)

RT-dpnPCR was performed as in RT-nPCR, except using two homologous and two complementary primers in each reaction $(0.225 \mu \mathrm{M}$ each primer, $\mathrm{H} 1, \mathrm{H} 3, \mathrm{C} 1$, and $\mathrm{C} 3$ for first PCR and $\mathrm{H} 2, \mathrm{H} 4, \mathrm{C} 2$, and $\mathrm{C} 4$ for second PCR).

\section{Results}

\section{Viral cDNA synthesis and amplification of the 3'-terminal regions of ACLSV genomes from apples}

Using the four primers, P1, P2, M1, and C4 (Fig. $1)$, corresponding to the conserved region among three complete nucleotide sequences of ACLSV genomes reported previously ${ }^{5,6,17}$, and another from apple strain MO- $5^{19}$, latent to $M$. prunifolia var. ringo, we attempted to amplify the cDNA of viral genomes in total RNA from apple trees containing each of the 15 ACLSV isolates. As summarized in Table 1, almost all combina- tions of the four primers permitted amplification of cDNA fragments in total RNA from apple trees containing each of the 15 ACLSV isolates. The sizes of the cDNA fragments for each primer pair agreed well with those expected based on the nucleotide sequence of the ACLSV genome. The cDNA fragments amplified with primer pair $\mathrm{P} 1$ and $\mathrm{M} 1$ resulted in amplification from all viral isolates, and these were the longest products $(1.8 \mathrm{~kb})$. They were further analyzed and confirmed to be viral cDNA by direct sequencing analysis, as described in the following section 3 .

\section{Genomic heterogeneity of ACLSV in apple trees}

To investigate whether viral genomes were heterogeneous in apple trees, the cDNA fragments of the region encoding both the $50 \mathrm{~K}$ and $\mathrm{CP}$ genes and the flanking $\mathrm{CP}$ gene prepared from the 13 isolates (Fig. 2 A) were analyzed in detail by SSCP. SSCP was performed at three running temperature conditions for polyacrylamide gel electrophoresis $\left(20,25\right.$, and $\left.40^{\circ} \mathrm{C}\right)$. SSCP at $25^{\circ} \mathrm{C}$ caused the separation of each of the cDNA fragments into the largest number of bands (Fig. 
Table 2. Comparison of base usage in partial cDNA nucleotide sequences of the ACLSV genome of 15 isolates

\begin{tabular}{|c|c|c|c|c|c|}
\hline \multirow[t]{2}{*}{ Isolate } & \multirow[t]{2}{*}{ Total } & \multicolumn{2}{|c|}{ Hetero } & \multicolumn{2}{|c|}{$\mathrm{R}+\mathrm{Y}$} \\
\hline & & Number & $\%$ & Number & $\%$ \\
\hline P-195 & $1626^{1)}$ & $215^{2)}$ & $13^{3)}$ & $139^{4)}$ & $65^{5)}$ \\
\hline P-195L & 1565 & 233 & 15 & 157 & 67 \\
\hline PK-32 & 1469 & 261 & 18 & 175 & 67 \\
\hline PK-51 & 1560 & 283 & 18 & 193 & 68 \\
\hline P-142 & 1307 & 212 & 16 & 147 & 69 \\
\hline P-143 & 1510 & 227 & 15 & 154 & 68 \\
\hline MK-8 & 1576 & 205 & 13 & 147 & 72 \\
\hline B-81 & 1566 & 90 & 5.8 & 55 & 61 \\
\hline P-202 & 1714 & 0 & 0 & 0 & - \\
\hline PK-5 & 1454 & 205 & 14 & 122 & 60 \\
\hline PI-25 & 1422 & 109 & 7.7 & 63 & 58 \\
\hline MK-1 & 1707 & 111 & 6.5 & 95 & 86 \\
\hline MK-9 & 1522 & 3 & 0.2 & 3 & 100 \\
\hline MO-31 & 1724 & 6 & 0.35 & 3 & 50 \\
\hline MO-41 & 1387 & 24 & 1.7 & 10 & 42 \\
\hline Consensus & 1558 & 591 & 38 & 322 & 55 \\
\hline
\end{tabular}

${ }^{1)}$ :The number of positions investigated by direct sequencing with more than two primers on the cDNA.

2) :The number of positions designated as a heterogeneous base, i.e. N, D, V, B, H, W, S, K, M, R or Y, by direct sequencing.

3) :The percentage of positions designated as a heterogeneous base to the total positions investigated.

4) :The number of positions designated as $\mathrm{R}(\mathrm{A}$ and $\mathrm{G})$ or $\mathrm{Y}(\mathrm{C}$ and $\mathrm{T}$ ) by direct sequencing.

${ }^{5)}$ :The percentage of positions designated as $\mathrm{R}$ or $\mathrm{Y}$ to the positions designated as heterogeneous bases.

2B) among the temperature conditions examined. The bands for nine isolates, P-195, P-195L, PK-32, P-142, P-143, PI-25, MK-8, PK-5, and MK-1, were separated into three to nine bands, whereas those for four isolates, P-202, MO-31, MK-9, and MO-41, were mainly separated into two bands. None of the isolates showed the same band pattern as any other isolate on SSCP analysis, except isolates P-195 and P-195L, which were, however, of the same origin. Due to the use of pairs of fluorescent-labeled primers, homogenous fragments could be separated into two bands, corresponding to strands that were homologous and complementary to the viral genome. This is why the cDNA fragments of the nine and four isolates may be comprised of one major sequence with two to four minor variants, and a major one, respectively.

\section{Direct sequencing of viral cDNAs}

Nucleotide sequences of the 3 '-terminal $1.8-\mathrm{kb}$ viral cDNA were investigated by direct sequencing. Insertions, deletions, and/or substitutions contained in some sequence variants but not in other variants in the same isolate sometimes prevented direct sequencing using some primers, although 14 primers were used for direct sequencing. The nucleotide sequencing data investigated using more than two primers were then considered to be available for subsequent analysis, and appear in DDBJ/ EMBL/GenBank nucleotide sequence databases with accession numbers AB060950 to AB060964. The direct sequencing results were consistent in terms of the heterogeneity of viral genomes in apple trees with those of the gel electrophoreses results described above. In each of the 15 cDNA sequences, many (5.8-18\%) heterogeneous positions were found in 11 isolates, which included nine isolates that may be comprised of two to four sequence variants according to SSCP; in comparison, the others $(0-1.7 \%)$ were suggested by SSCP to be occupied with a major type sequence (Table 2). These 15 sequences and two complete nucleotide sequences of genomic cDNAs from apple trees $\left(\mathrm{P} 205^{17}\right.$ and MO- $\left.5^{19}\right)$ were aligned (Fig. 3A). About one-third of the 1558 positions of the consensus nucleotide sequence were designated as heterogeneous. $\mathrm{R}$ and $\mathrm{Y}$ occupied more than half of the heterogeneous positions. In addition, most of 
the heterogeneous positions were located at the third position in codons in the $50 \mathrm{~K}$ and CP ORF (partly shown in Fig. 3B). Although heterogeneous positions were dispersed throughout the region analyzed, the longest nucleotide sequence that was shared among/in all isolates was a stretch of 35 nucleotides (Fig. 3B, doubleunderlined) in the region encoding both the $50 \mathrm{~K}$ and $\mathrm{CP}$ (Fig. 3A, underlined).

\section{Comparison of RT-PCR procedures for detection of ACLSV in RNA extracts from apple tissues}

As the four primers, P1, P2, M1, and C4, designed according to the regions conserved among four complete nucleotide sequences (Fig. 1), worked well for amplifying the genomic cDNAs of ACLSV isolates from apple trees (Table 1), we preliminarily attempted to detect ACLSV in apple tissue extracts by PCR-based techniques with these four primers (Fig. 4). RT-nested PCR (RT-nPCR) with primers P1 and M1 for first PCR and P 2 and $\mathrm{C} 4$ for second PCR amplified cDNA fragments of the expected lengths in total RNA from all tissues, whereas RT-PCR with primers P2 and C4 failed to amplify the cDNA in total RNA from leaf or bark in summer. However, RT-nPCR could not consistently amplify cDNA in total RNA from several summer leaves containing different isolates (data not shown).

To detect ACLSV isolates in apple tissues consistently, six degenerate primers, $\mathrm{H} 1, \mathrm{H} 3, \mathrm{H} 4, \mathrm{C} 1, \mathrm{C} 2$, and $\mathrm{C} 3$, were re-designed considering genetic diversities detected by direct sequencing (Fig. 1, primers for diagnosis). RT-dual-primed nested PCR (RT-dpnPCR) using primers $\mathrm{H} 1, \mathrm{H} 3, \mathrm{C} 1$, and $\mathrm{C} 3$ for first PCR and, H2, H4, $\mathrm{C} 2$, and $\mathrm{C} 4$ for second PCR, as well as RT-PCR using primers $\mathrm{H} 4$ and $\mathrm{C} 4$ and RT-nPCR using primers $\mathrm{H} 3$ and $\mathrm{C} 3$ for first PCR and $\mathrm{H} 4$ and $\mathrm{C} 4$ for second PCR, were used to detect ACLSV in apple tissue extracts. Because RT-PCR could not amplify the cDNA fragments of the expected length amplified with $\mathrm{C} 4$ and $\mathrm{H} 4$ in one apple leaf and all bark extracts (Fig. 5A), RT-nPCR was tried for detection of ACLSV in these samples. However, the sensitivity and reliability for detecting ACLSV depended on the primers used. RT-nPCR with primers $\mathrm{H} 2$ and $\mathrm{C} 2$ for first PCR (827 bp of amplicon) and H4 and C4 for second PCR (188 bp of amplicon) could not amplify viral cDNA in two of five leaf extracts (data not shown) in which even RT-PCR with primers $\mathrm{H} 4$ and $\mathrm{C} 4$ could amplify viral cDNA (Fig. 5A, lanes 1 and 4). However, RT-nPCR with primers H3 and C3 for first PCR (305 bp of amplicon) and $\mathrm{H} 4$ and $\mathrm{C} 4$ for second PCR (188 bp of amplicon) could consistently amplify viral cDNA in RNA extracts from both leaves and bark during the active and dormant seasons (Fig. 5B), suggesting that shorter fragments should be selected for amplification by RT-nPCR and the reliable detection of ACLSV. Furthermore, RT-dpnPCR with primers $\mathrm{H} 1, \mathrm{H} 3, \mathrm{C} 1$, and $\mathrm{C} 3$ for first PCR and $\mathrm{H} 2, \mathrm{H} 4, \mathrm{C} 2$, and $\mathrm{C} 4$ for second PCR produced an enhanced amplification of the cDNA with the innermost primer pair, $\mathrm{H} 4$ and $\mathrm{C} 4$, compared to RTnPCR (Fig. 5C), except in one leaf extract (Fig. 5B, C, lane 1). RT-dpnPCR however amplified the viral cDNAs with primer pairs, $\mathrm{H} 4$ and $\mathrm{C} 2$, and $\mathrm{H} 2$ and $\mathrm{C} 2$ from leaf samples too (Fig. 5C, lanes 1-5).

Detection limits of RT-PCR, RT-nPCR, and RTdpnPCR were determined by making 10 -fold serial dilutions of total RNA extracts from an infected leaf. RTnPCR and RT-dpnPCR had the same sensitivity. The specific cDNAs were detected up to dilutions of $10^{-4}$ with healthy tissue extract (corresponding to $40 \mathrm{ng}$ of infected leaf tissue) by RT-nPCR and RT-dpnPCR, which were $10^{4}$-fold more sensitive than RT-PCR. The experiment was repeated three times and essentially the same results were obtained (data not shown).

\section{Discussion}

This study describes a process for the sensitive and reliable detection in apple trees of ACLSV, representing several variants differing in genomic nucleotide sequence.

SSCP analysis showed the existence of sequence variations in the isolates from apple trees but did not allow a detailed examination of the composition of the sequence variants (Fig. 2). Direct sequencing analysis provided intimate information on viral sequence variations in apple trees, although the drawbacks of using cDNA fragments amplified by RT-PCR for direct sequencing should be considered: the composition of the population may be normalized and/or biased through the process of amplification compared with that of the template viral genome. All ACLSV isolates that induced a decline in the condition of the rootstock were shown to have two to four sequence variants, except for the isolate P-202, which was propagated in an apple seedling following isolation through a single local lesion in a Chenopoium quinoa leaf infected with the parental virus ${ }^{20}$. However, ACLSV isolates that did not induce a decline in rootstock were occupied with a major type sequence, except for MK-1. One-third of the positions in the consensus nucleotide sequence of the isolates were heterogeneous, and more than half of these were R or Y (Table 2). The heterogeneous positions among/in isolates were frequently located at the third positions of codons in the ORFs of $50 \mathrm{~K}$ and $\mathrm{CP}$ genes (Fig. 3), suggesting that many of the sequence variations would not alter the 
(A)

$5811^{\mathrm{a}}$

5' r tnagyccyttyar rar rgcytctgacytnatgawycaytggaatgarttygtnttyaargtyatgccrgargayatngcdggdgayggyttyagrytrg cntcnathccdgtbathcchkvbtcwgar gtbmar gcdgtnhtnar raar agr gadr ryacnaaytayr tkcaytggggr gcdytdtcnatwtcnatwga ygcnYTNTTYARRAARAAYGCHGGDGTNTCNGGNTGGTGYTAYGTNTMYGAYAHYAGRKGGGARACNTTTGARCARGCNAWGYTVCARAARTTYMGNTTY AAYYTNGAYAGYGGNTCVGCNACDYTGGKVACNTCNCCRAAYTTYCCNGTNTCDYTDGAYGAYCCNGGHYTBTCVAAYTCVATHWGBGTNGCNGTVATGT TYGAGAAYYTNAAYTTYAARYTNGANAGYTAYCCNATHAGYGTNAGRGTNGGNAMYATGTGYMGRTTCTTYGAYAGYTTCYTGAGYWRHGTBARRAAYAR RRWKGAYTCHAAyttyhtdytdgar gchkcnaatgcdgahccnytDGGNGCNRGNGYYTTYGGDTTTGADSAVGAYGAYCARGTBWSYGARYBRTTYMAY TAYRTHCMRACHGKNCCNACHCARGCNATYAARTCVAGRGARCAYGARRTHCCNARRGGNHTDTTyggnatdmtkggnaar aar amngtbaarwchttyg arttygchtcnggntcdar r r ryhtvrrvar rmkrmr rccdmarmgvgsvrgrncnhbdgr ragrtcndhhagcywragrkwkdyycctggatttar gtc ccaggrygagar arttgaacwycaaggnttrkcractgaywnngayTTYGARAAYTTYYYSRRRVRyr aRGGVARRRGNRARRCTGGANCHRARTCCNTT DHTTCAGARGGGTCATCYDTBGAYAACATHTCTNCAAGRGARTTTCARTTYGCTMGACARRRYMARaagGMGAMRRAgrATGGCRRCRRTDYTVAAYYTIN CARYTAAARGTRGACGCAGATYTGAARGYDTTYCTRSCCGYRGAAGGCAGACCCCTTCATGGAAAGACAGGGGCAATHYTGGAACWGAYRYTGGAGKCCA TCTTMKCGAACATAGCRATHCARGGVACVTCRGARCARACVGARWTYYTGGAYNKDVHNGTGGARGTSAARTCVATGGAGGAYCARMARGTBDRTVRRNT CNTWCAAYYTGARRDMRGTRGKSRRYHTNRTCAARVHHTTCARRACTACMTCTTYRGAYCCRAAYATHARCRRNATGACYTTCCGYCADGTBTGTGARGS Httygchccbgaggcvagr raygggytsgthaarytraar tayaaagggktytthmcndaccthtttwcdachaygccngaagtdvgrnrbnardwmyyc vgagytnatgttygayttyahyaar rgbytnaayatgttyatmatgaayaargcycarcar aar gtvathacyaayatgaaycggcgtcttttrcaract garttygcaaaragygaraaygaggcvaarmtbtcrtctgtyacractgayctttgcr $3^{\prime}$ $7360^{a}$

(B)

CONS
P-205
P-195
P-195L
PK-32
PK-51
P-142
P-143
MK-8
B-81
P-202
PK-5
PI-25
MK-1
M0-31
M0-41
MK-9
M0-5

CONS

$\mathrm{P}-205$

P-195

P-195L

PK-32

PK-51

$\mathrm{P}-142$
$\mathrm{P}-143$

MK-8

B-81

P-202

PK-5

$\mathrm{PI}-25$

MK-1

M0-31

M0-41

MK-9 $6784^{\mathrm{a}}$

ATGGCRRCRRTDYTVAAYYTNCARYTAAARGTRGACGCAGATYTGAARGYDTTYCTRSCCGYRGAAGGCAGACCCCTTCATGGAAAGACA ATGGCGGCAGTGCTGAACCTCCAATTAAAAGTGGACGCAGATCTGAAAGCGTTCCTGGCCGCAGAAGGCAGACCCCTTCATGGAAAGACA

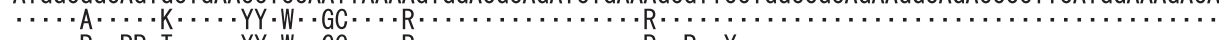

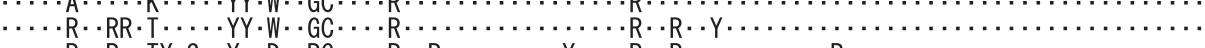

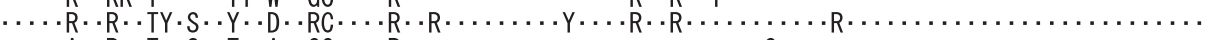

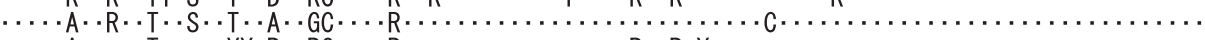

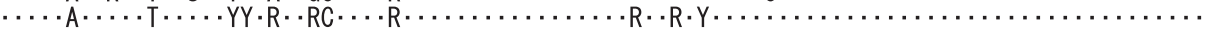

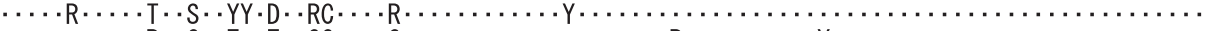

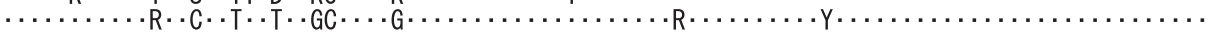

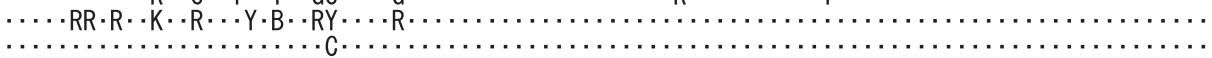

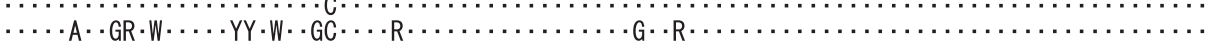

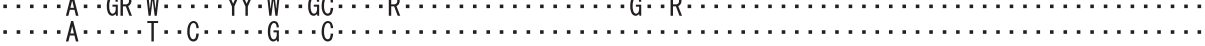

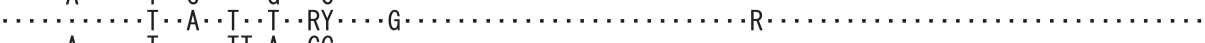

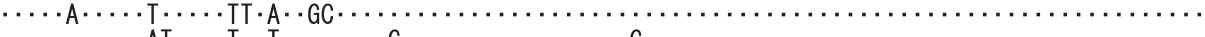

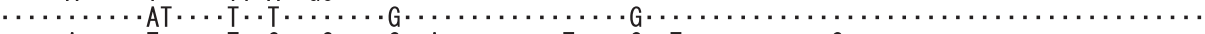

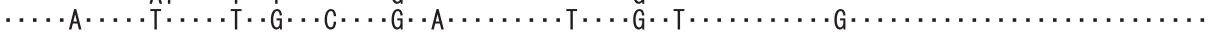

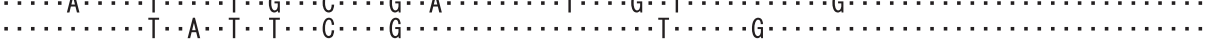

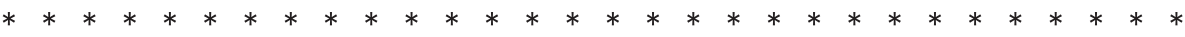

$6963^{\mathrm{a}}$ GGGGCAATHYTGGAACWGAYRYTGGAGKCCATCTTMKCGAACATAGCRATHCARGGVACVTCRGARCARACVGARTTYYTGGAYNKDVYG GGGGCAATTCTGGAACAGACACTGGAGGCCATCTTCGCGAACATAGCGATACAGGGGACCTCGGAACAAACAGAGTTCCTGGACGTGCTG

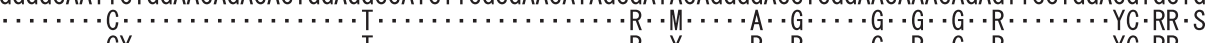

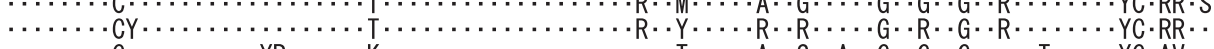

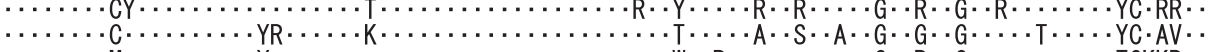

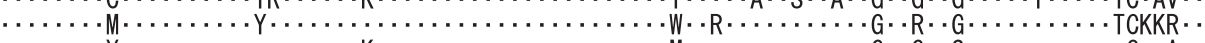

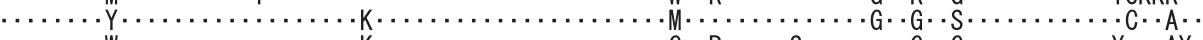

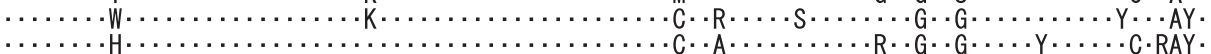

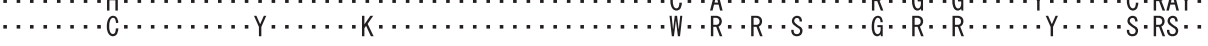

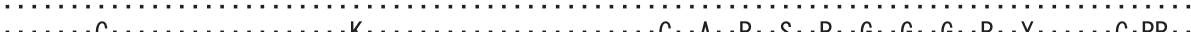

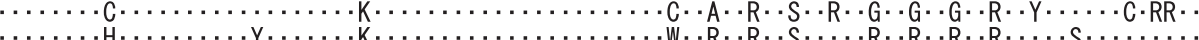

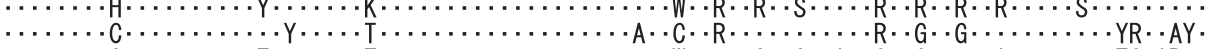

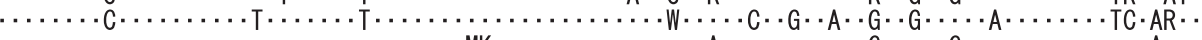

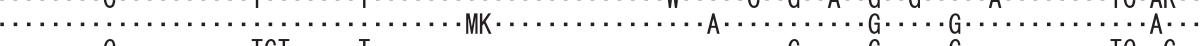

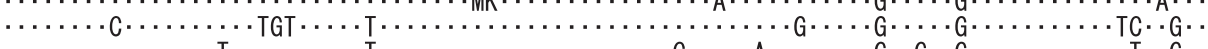

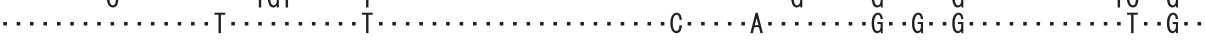

Fig. 3. Consensus nucleotide sequence of partial viral cDNA among 17 ACLSV isolates from apple trees (A), of which part of the sequence underlined is the overlapping region between $50 \mathrm{~K}$ protein and capsid protein $(\mathrm{CP})$

Alignment of each nucleotide sequence of ACLSV isolates was also shown (B). The partial nucleotide sequences of the virulent isolate P-205, which induced a decline in condition of the rootstock ${ }^{17}$, and the latent isolate MO- $5^{19}$ were also aligned. (A) Uppercase and lowercase letters in the consensus nucleotide sequence indicate consensus among all 17 isolates and more than 10 isolates, respectively. The gray-shaded sequences are the regions corresponding to degenerate primers ( $\mathrm{H} 1$ to $\mathrm{H} 4$ and $\mathrm{C} 4$ to $\mathrm{C} 1$ in order from $5^{\prime}$ to $3^{\prime}$ ) for detection of ACLSV. The boxed nucleotide sequences are the regions corresponding to the primers used in a previous study for detection of $\mathrm{ACLSV}^{9}$. a: Numbering is consistent with that of isolate P-205 ${ }^{17}$. (B) Asterisks and positions before asterisks are the third positions of codons in $\mathrm{CP}$ and a $50 \mathrm{~K}$ open reading frame, respectively. The double-underlined region of 35 nucleotides was the longest nucleotide sequence that was shared among/within all isolates. The gray-shaded nucleotide sequence is the region corresponding to primer $\mathrm{C} 4$. In nucleotide sequences of primers, symbols are represented as Fig. 1. 


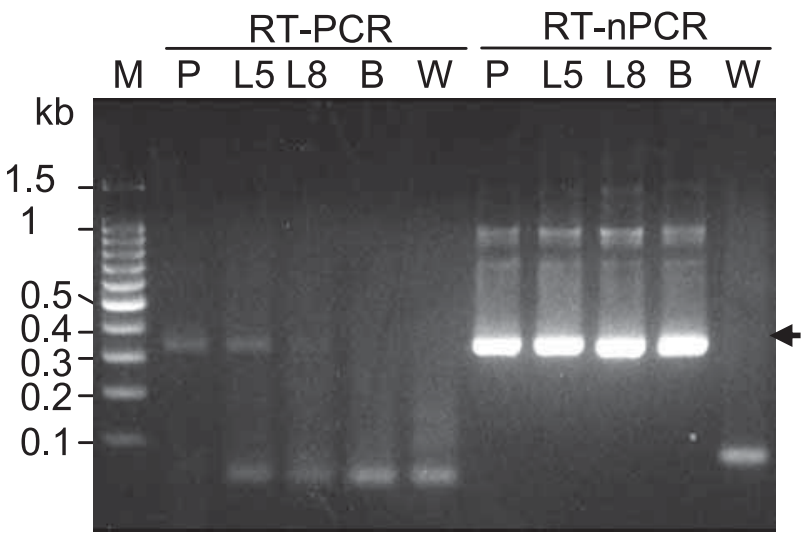

Fig. 4. Comparison of RT-PCR with primers $P 2$ and C4; RT-nested PCR (RT-nPCR) with primers $\mathrm{P} 1$ and $\mathrm{M} 1$ for first PCR and P2 and $\mathrm{C} 4$ for second PCR

These products amplified from total RNA extracts of apple petals (lane P), leaves in May and August (lanes L5 and L8, respectively), and bark in August (lane B) infected with ACLSV isolate P-195 were fractionated with $1.5 \%$ agarose gel electrophoresis, and the products were visualized with ultraviolet illumination after staining with ethidium bromide. Arrowhead indicates the position of a expected PCR products with primers, $\mathrm{P} 2$ and $\mathrm{C} 4$. Lane $\mathrm{M}$ is a 100-bp ladder DNA molecular weight marker. Lane $\mathrm{W}$ is the negative control (amplification without template).

amino acid sequences of the $50 \mathrm{~K}$ or $\mathrm{CP}$ genes. It was also interesting that P-202 remained homogeneous and did not accumulate mutations more than 20 years after its isolation ${ }^{20}$. Magome et al. ${ }^{12}$ reported that the composition of ASGV sequence variations differed among different tissues and changed through different host plants. This is probably applicable in the case of ACLSV isolates. Therefore, successive accumulation of substitutions, as well as topworking, seem to partly account for the mixture of sequence variants contained in apple trees, but the accumulation would require propagation of each isolate for dozens of years, under different circumstances (e.g., different host species, tissues, and/or growth conditions). It was reported that an ACLSV isolate from a French peach plant (LS16) is composed of a mixture of three sequence variants ${ }^{2}$. The results of the present study demonstrated a similar phenomenon for ACLSV isolates in apple trees. Similar results were additionally reported for viruses and viroids, e.g., ASGV in apple, European pear and Japanese pear ${ }^{11,12}$, citrus viroids $^{7}$, and grapevine viroids ${ }^{16}$, suggesting that the phenomenon is universal for viruses and viroids in woody
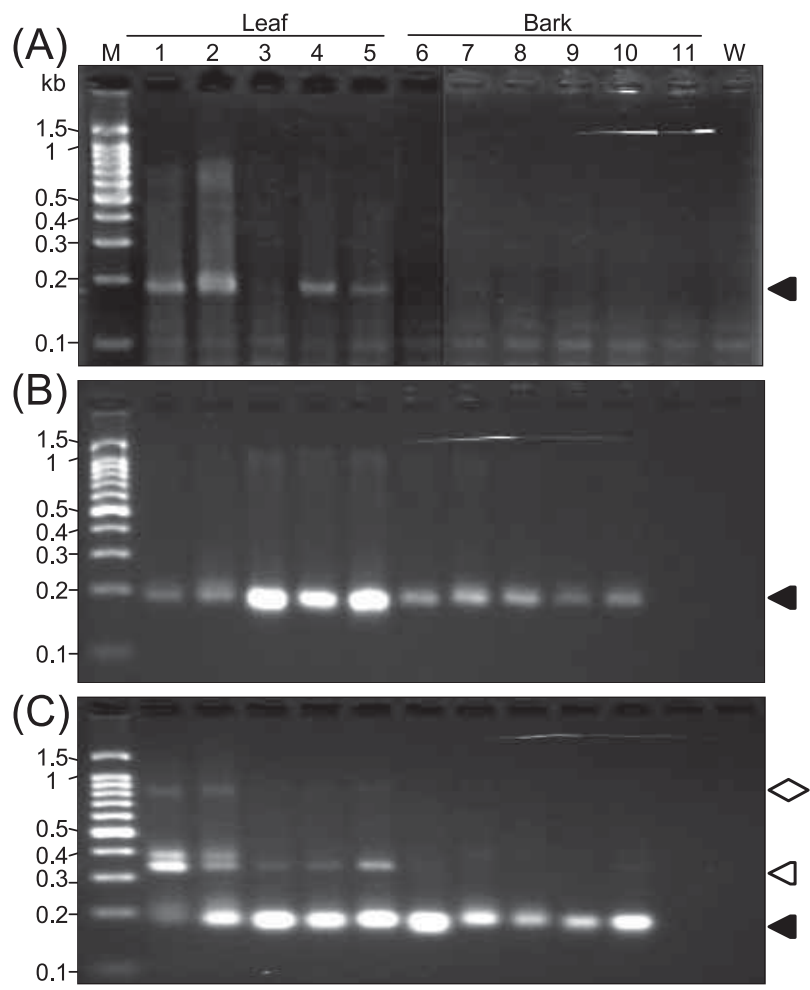

Fig. 5. Comparison of RT-PCR with primers $\mathrm{H} 4$ and C4 (panel A); RT-nested PCR (RT-nPCR) with primers $\mathrm{H} 3$ and $\mathrm{C} 3$ for first $\mathrm{PCR}$, and $\mathrm{H}$ 4 and C4 for second PCR (panel B); and RTdual primed nested PCR (RT-dpnPCR) with primers H1, H3, C1, and $\mathrm{C} 3$ for first PCR, and $\mathrm{H} 2, \mathrm{H} 4, \mathrm{C} 2$, and $\mathrm{C} 4$ for second PCR (panel C)

These products were amplified from total RNA extracts of apple leaves in May (lanes 1-5) and bark in February (lanes 6-10) infected with several apple chlorotic leaf spot virus isolates: P-202 (lanes 1 and 6), P-195 (lanes 2 and 7), P-143 (lanes 3 and 8), MO-41 (lanes 4 and 9), and MO-31 (lanes 5 and 10), and virus-free bark in February (lane 11). The samples were fractionated with $1.5 \%$ agarose gel electrophoresis and products were visualized with ultraviolet illumination after staining with ethidium bromide. Closed and open arrowheads and open diamond indicate the positions of expected PCR products with primers, H4-C4 (188 bp), H4-C2 (339 bp) and H2-C2 (827 bp), respectively. Lane $M$ is a 100 -bp ladder DNA molecular weight marker. Lane W is the negative control (amplification without template).

plants.

Previous reports ${ }^{2,9}$ used oligonucleotide primers designed from the nucleotide sequence of the single plum isolate, ACLSV-P8635 ${ }^{5}$ PCR primers should thus be de- 
signed considering the sequence varieties of viral genomes among ACLSV isolates for reliable detection of the virus. Actually, the primers used in a previous study $^{9}$ would cause mismatches with the ACLSV isolates analyzed in this study (Fig. 3A), possibly resulting in inefficient amplification of viral cDNAs with the primers. To establish a PCR-based procedure for the detection of ACLSV having genomic diversity among isolates, the use of degenerate primers, part of which keep a high complementarity to each genome of the isolates, would be required. Direct sequencing is suitable for design of degenerate primers. We could easily detect genomic polymorphism among heterogeneous cDNAs in each of isolates by direct sequencing: a single sequencing signal was detected in each position of the conserved sequence but two or more signals were detected in the other sequence of heterogeneous cDNA. As a result, eight degenerate primers for PCR-based detection of all of the ACLSV isolates analyzed were designed corresponding to genomic diversities detected by direct PCR.

RT-nPCR using the primers $\mathrm{H} 3$ and $\mathrm{C} 3$ for first PCR, and $\mathrm{H} 4$ and $\mathrm{C} 4$ for second PCR could detect ACLSV in all samples, including those extracted from dormant apple bark, in which RT-PCR could not detect the virus (Fig. 5). This result was caused by a lower concentration of ACLSV in dormant bark than in spring leaves; nevertheless RT-nPCR could detect ACLSV in bark because of its $10^{4}$-fold higher sensitivity for ACLSV detection compared to that of RT-PCR. This study is the first report applying nested PCR to the detection of ACLSV, and RT-nPCR seems to be preferred to RT-PCR for the detection of ACLSV in low and uneven concentrations in apple tissues. Additionally, we developed RT-dpnPCR methods in the present study. Because RT-dpnPCR is performed using two homologous and two complementary primers in each round of PCR, four kinds of DNA fragment will be amplified simultaneously by PCR with the four combinations of primers although the amplification rates of the DNA fragments will differ in each primer combination. The DNA fragment that is amplified with the inner primer pair will accumulate the most in the amplified fragments. RT-dpnPCR gave enhanced amplification of the viral cDNA compared with RT-nPCR with the inner primer pair (H4 and C4; Fig. 5). However, the 10-fold dilution end-points of apple leaf extract required to detect ACLSV were the same in RT-nPCR and RTdpnPCR, indicating that the difference in sensitivity is less than 10-fold. In addition, RT-dpnPCR somewhat amplified not only viral cDNAs with the inner primer pair but also with the other pairs in leaf extracts (Fig. 5
$\mathrm{C}$, especially in lane 1). Although these results suggest that there is still some room for improvement of RTdpnPCR, RT-dpnPCR have a potential advantage over RT-nPCR in the consistent detection of viruses with genomic diversity among isolates and heterogeneity within each isolate. Because RT-dpnPCR use two homologous and two complementary primers in each round of PCR, both might be able to complementarily amplify the viral cDNA fragment with the other primers even if one homologous and/or one complementary primer does not work due to viral genomic variation leading to a mismatch, whereas RT-nPCR cannot. Yaegashi et $\mathrm{al}^{18}$ has recently reported that phylogenic analysis of CP amino acid sequences among ACLSV isolates divided them into two clusters, P-205 and B6 types. When the genomic sequences of the ACLSV isolates used in the study ${ }^{18}$, the nine Japanese isolates [P205 (GenBank accession no. D14996), MO-5 (AB 326225), A4 (AB326223), B6 (AB326224), GC10a (AB 326226), GC10c (AB326227), GC10f (AB326228), GC 10h (AB326229) and GC10j (AB326230)] and three European isolates [P863 (M58152), PBM1 (AJ243438) and BAL1 (X99752)], were aligned with the degenerate primers, H1-H4 and C1-C4. Thirty mismatches were detected on the aligned nucleotide sequences between viral genomes and the four primers, and 28 of 30 were included in B6 type isolates. Thus, the degenerate primers ideally need to be refined based on the genomic sequences of B6 type isolates though these primers might even be efficient for detection of B6 type ones because the mismatches are not located at 3'-termini of the degenerate primers.

\section{Acknowledgments}

We thank M. Sekimura for her excellent laboratory assistance. This work was partly supported by grants from the Ministry of Agriculture, Forestry and Fisheries of Japan, in the project "Gene Analysis of Pathogens."

\section{References}

1. Bertolini, E. et al. (2003) Multiplex nested reversetranscription -polymerase chain reaction in a single tube for sensitive and simultaneous detection of four RNA riruses and pseudomonas savastanoi pv. savastanoi in olive trees. Phytopathol., 93, 286-292.

2. Candresse, T. et al. (1995) An immunocapture-PCR assay adapted to the detection and the analysis of the variability of apple chlorotic leaf spot virus. Acta Hortic., 386, 136-147.

3. Desvignes, J.C. \& Boyé, R. (1989) Different diseases caused by the chlorotic leaf spot virus on the fruit 
trees. Acta Hortic., 235, 31-38.

4. Fridlund, P.R. (1973) Distribution of chrolotic leaf spot virus in apple budsticks. Plant Dis. Reptr., 57, 865869.

5. German, S. et al. (1990) Nucleotide-sequence and genomic organization of Apple chlorotic leaf-spot Closterovirus. Virol., 179, 104-112.

6. German-Retana, S. et al. (1997) Complete nucleotide sequence of the genome of a severe cherry isolate of apple chlorotic leaf spot trichovirus (ACLSV). Arch. Virol., 142, 833-841.

7. Ito, T., Ieki, H. \& Ozaki, K. (2000) A population of variants of a viroid closely related to citrus viroid-I in citrus plants. Arch. Virol., 145, 2105-2114.

8. Kanno, Y., Yoshikawa, N. \& Takahashi, T. (1991) Detection of apple chlorotic leaf spot virus by dot-blot hybridization. Ann. Phytopath. Soc. Jpn., 57, 278-282.

9. Kinard, G.R., Scott, S.W. \& Barnett, O.W. (1996) Detection of apple chlorotic leaf spot and apple stem grooving viruses using RT-PCR. Plant Dis., 80, 616621.

10. Lister, R.M. (1970) Apple chlorotic leaf spot virus. C. M.I./A.A.B Descriptions of Plant Viruses. No. 30. Commonw. Mycol. Inst./Assoc. Appl. Biol., Kew, Eng.

11. Magome, H. et al. (1997) Molecular variability of the genomes of capilloviruses from apple, Japanese pear, European pear, and citrus trees. Phytopathol., 87, 389396.

12. Magome, H., Yoshikawa, N. \& Takahashi, T. (1999) Single-strand conformation polymorphism analysis of apple stem grooving capillovirus sequence variants. Phytopathol., 89, 136-140.

13. Martelli, G.P., Candresse, T. \& Namba, S. (1994) Trichovirus, a new genus of plant-viruses. Arch. Virol., 134, 451-455.

14. Olmos, A. et al. (1997) Simultaneous detection and typing of plum pox potyvirus (PPV) isolates by
heminested-PCR and PCR-ELISA. J. Virol. Methods, 68, 127-137.

15. Olmos, A. et al. (1999) New device and method for capture, reverse transcription and nested PCR in a single closed-tube. Nucleic Acids Res., 27, 1564-1565.

16. Polivka, H., Staub, U. \& Gross, H.J. (1996) Variation of viroid profiles in individual grapevine plants: Novel grapevine yellow speckle viroid 1 mutants show alterations of hairpin I. J. Gen. Virol., 77, 155-161.

17. Sato, K., Yoshikawa, N. \& Takahashi, T. (1993) Complete nucleotide-sequence of the genome of an apple Isolate of Apple chlorotic leaf-spot virus. J. Gen. Virol., 74, 1927-1931.

18. Yaegashi, H. et al. (2007) Combinations of two amino acids (Ala40 and Phe75 or Ser40 and Tyr75) in the coat protein of apple chlorotic leaf spot virus are crucial for infectivity. J. Gen. Virol., 88, 2611-2618.

19. Yaegashi, H. et al. (2007) Apple chlorotic leaf spot virus $50 \mathrm{kDa}$ movement protein acts as a suppressor of systemic silencing without interfering with local silencing in Nicotiana benthamiana. J. Gen. Virol., 88, 316324.

20. Yanase, H. (1974) Studies on apple latent viruses in Japan. Bull. Fruit Tree Res. Stn., C1, 47-109.

21. Yanase, H. et al. (1979) Back transmisson of apple chlorotic leafspot virus (type strain) to apple and production of apple topworking disease symptoms in Maruba Kaido (Malus prunifolia Borkh. Var. ringo Asami). Ann. Phytopath. Soc. Jpn., 45, 369-374.

22. Yanase, H. et al. (1986) Detection of different strains of apple chlorotic leafspot virus and apple stem grooving virus by direct double antibody sandwich method and modified indirect ELISA (F(ab')2 procedure). Bull. Fruit Tree Res. Stn., A13, 69-81.

23. Yoshikawa, N. \& Takahashi, T. (1988) Properties of RNAs and proteins of apple stem grooving and apple chlorotic leaf-spot viruses. J. Gen. Virol., 69, 241-245. 